\title{
Suicidal Carbon Monoxide Poisoning Using Motor Vehicle Exhaust in an Open Space
}

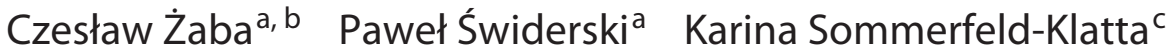 \\ Zbigniew Żaba $^{d}$ Katarzyna Pluta-Hadas $^{\mathrm{e}}$ Monika Urbaniak $^{\mathrm{e}}$ \\ a Department of Forensic Medicine, Poznan University of Medical Sciences, Poznan, Poland; ${ }^{\mathrm{b}}$ Road Accidents \\ Analysis Section in Poznan, Department of Road Accidents Analysis, Institute of Forensic Research in Krakow, \\ Poznan, Poland; ' Department of Toxicology, Poznan University of Medical Sciences, Poznan, Poland; \\ ${ }^{\mathrm{d}}$ Department of Teaching Anesthesiology and Intensive Therapy, Poznan University of Medical Sciences, Poznan, \\ Poland; e Department of Medical Law and Medical Care Organization and Management, Poznan, Poland
}

\section{Significance of the Study}

- This study shows that long exposure to carbon monoxide in an open space can cause acute carbon monoxide poisoning. This should be considered by forensic, emergency, and occupational professionals for diagnosing poisoning by unknown agents.

\section{Keywords}

Carbon monoxide poisoning $\cdot$ Suicide $\cdot$ Car exhaust

\begin{abstract}
Objectives: A rare case of a suicidal use of gases from the car exhaust system of the car petrol engine in an open space is presented. Clinical Presentation and Intervention: To verify suicidal intent of poisoning, an experimental reconstruction of the crime scene was performed. This demonstrated that appropriately long exposure to carbon monoxide with unfavorable weather conditions can cause acute carbon monoxide poisoning in an open space. Conclusions: This case was studied to observe the pattern of fatal carbon monoxide poisoning in an open space. This might be helpful for forensic medicine, emergency medicine, and occupational medicine.

(c) 2019 The Author(s)

Published by S. Karger AG, Basel
\end{abstract}

\section{KARGER}

E-Mail karger@karger.com www.karger.com/mpp

\section{Introduction}

Carbon monoxide (CO) poisoning, together with ethyl alcohol and medication poisonings, are the most frequent causes of fatal poisonings [1]. The main sources responsible for the exposure to high concentrations of $\mathrm{CO}$ are fires, any type of leakage of heating installation using combustion, and car exhaust fumes [2-4].

\section{Case Report}

A corpse of a 60-year-old male was found in a forest. It was established on site that the deceased had a taxi driver license in his pocket, and he was lying behind a Daewoo Nubira with a 1.6-L capacity $\left(1,598 \mathrm{~cm}^{3}\right), 16 \mathrm{~V}$ DOHC, $106 \mathrm{hp}$ petrol engine, marked as a taxi cab. According to the statement of the policemen present on site, the man was lying on his back with his head in the proximity 
Fig. 1. Reconstruction of the presumed body position during lawsuit experiment.

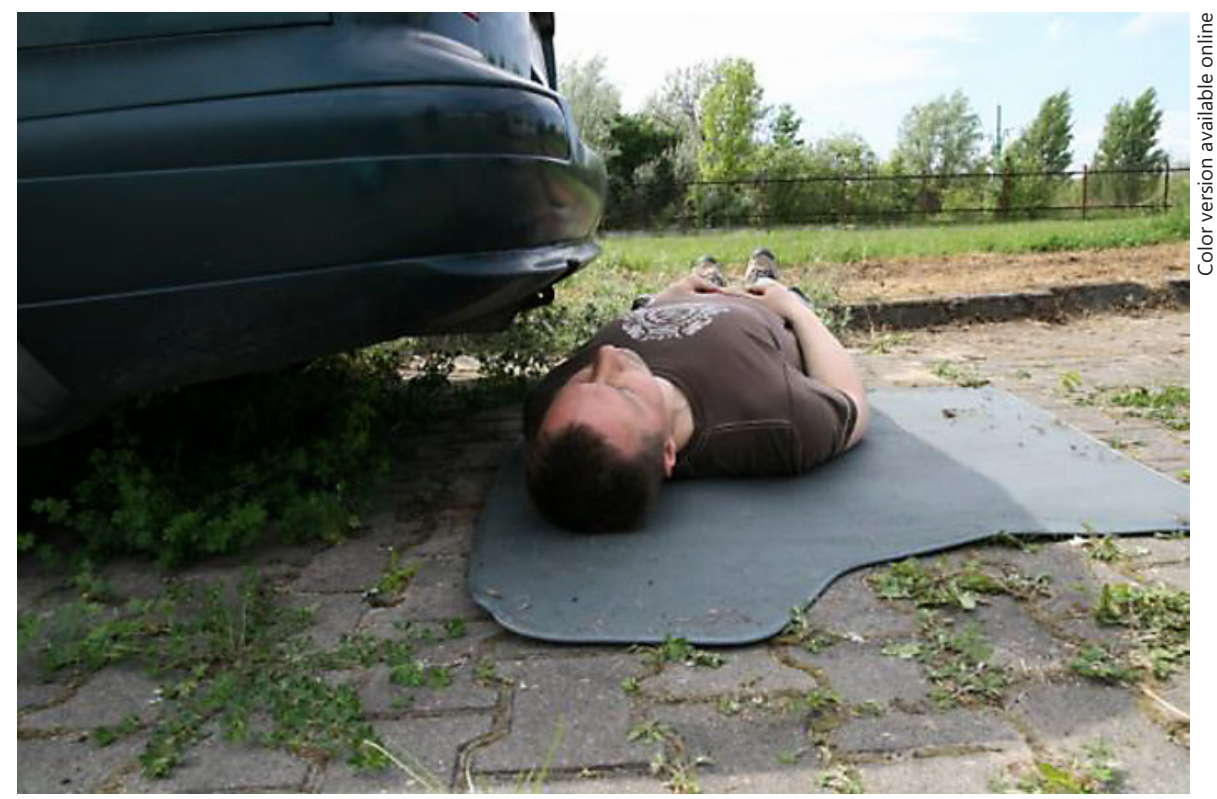

of the exhaust system of the car, on a car floor mat. However, as a result of emergency proceedings performed by the paramedics, the man was removed from the rear of the car. Investigation showed that the car key was in the ignition in the "on" position, which suggested that the car engine was working; on the front passenger seat, there was a notebook with the following words: "do not blame anyone, I'm alone..."; there were two cans of beer next to the handbrake lever. The deceased was not covered in blood, his clothing was not damaged, there were no apparent external injuries that would suggest the possible participation of a third party.

Postmortem analysis revealed the presence of cerebral edema, focal pulmonary edema, pleural thickening within the apices of both lungs, cholecystolithiasis, passive congestion of internal organs, and liquid blood both in the blood vessels and heart chambers.

No medical information about the deceased man were available, but histopathology of the tissue samples taken during the autopsy revealed no signs of chronic diseases of the internal organs. Body core temperature of the corpse was not measured at the death scene. The chemical-toxicological test did not reveal the presence of alcohol in the blood. Urine was positive for alcohol, its concentration being $0.3 \%$. Alcohol found only in the victim's urine indicates that at the time of death, metabolism of alcohol was in a late stage of elimination. Total hemoglobin concentration was $14.6 \mathrm{~g} /$ dL. Blood carboxyhemoglobin level was $80 \%$ and was measured using a CO-oximeter. The test did not show the presence of other intoxicants and psychotropic substances in blood and urine. It was established that the direct cause of death was acute $\mathrm{CO}$ poisoning.

Further investigation included the experimental reconstruction aiming at establishing the concentration of $\mathrm{CO}$ given off by the petrol engine of the vehicle. The experiment employed the vehicle found on the site. The measurements were taken under similar weather conditions as on the day the cadaver was found. Based on a report from the Institute of Meteorology and Water Manage- ment, the weather conditions were as follows: altitude $65 \mathrm{~m}$ above sea level, wind speed $0 \mathrm{~m} / \mathrm{s}$, temperature $0{ }^{\circ} \mathrm{C}$, humidity $93 \%$, and ambient pressure $757 \mathrm{~mm} \mathrm{Hg}$.

To measure the concentration of CO, ALTAIR PRO gauges were used, calibrated only for CO measurements. Reproducibility of the instrument is $\pm 5 \mathrm{ppm}$ or $10 \%$ reading, whichever is greater (in the normal temperature range of $0-40^{\circ} \mathrm{C}$ ). Range of measurement is $0-1,500 \mathrm{ppm}$, and the resolution is $1 \mathrm{ppm}$. When ALTAIR PRO is calibrated only for CO measurements, there is no possibility that any other content within the motor vehicle exhaust could mislead the sensor.

First, the proper distance between the vehicle and the gauges was established based on the place in which the body of the deceased was lying, and to do so, a person whose height and body mass was similar to that of the described man (Fig. 1) participated in the experiment. After that, the engine was started, and the measurements were taken. The height of the exhaust pipe of the silencer was $26 \mathrm{~cm}$ above the ground. The gas gauge was placed at the height of $20 \mathrm{~cm}, 10 \mathrm{~cm}$ away from the outlet of the exhaust pipe.

\section{Results}

During the 10 -min measurement, the readouts of $\mathrm{CO}$ concentrations were recorded. They were variable in range, depending on the direction and force of wind gusts. Momentary readouts showed high concentrations of CO, from 167 to $790 \mathrm{ppm}\left(203-974 \mathrm{mg} / \mathrm{m}^{3}\right)$, while the constant level of results was maintained at 45-200 ppm $\left(55.5-247 \mathrm{mg} / \mathrm{m}^{3}\right)$ and at 0-250 ppm $\left(0-308 \mathrm{mg} / \mathrm{m}^{3}\right)$. 


\section{Discussion}

$\mathrm{CO}$ poisoning from petrol engine exhaust is most commonly accidental. CO poisoning is one of the less common methods of committing suicide. In Denmark, just $11.2 \%$ of the men and $3.7 \%$ of the women who committed suicide chose this method [5]. Such an incident usually occurs in a closed space, such as a garage, or in a car with tightly closed windows. Those in an open environment are rare [6]. In the United States, inhalation of car exhaust is responsible for nearly all suicides by $\mathrm{CO}$ poisoning [7].

In a technically efficient car, the average $\mathrm{CO}$ concentration is ca. $12 \mathrm{ppm}$, while outside it is only ca. $2-5 \mathrm{ppm}$ [8]. The widely spread use of catalytic converters, which decrease the amount of $\mathrm{CO}$ in the exhaust fumes from 3.5 to ca. $0.5 \%$, seems to be the reason why there has been a substantial decline in the number of suicides committed by poisoning with $\mathrm{CO}$ from the exhaust system of car engines [9]. This relationship is most apparent while correlating the increase in the number of cars equipped with catalytic converters and the decrease in the number of suicides with the use of car exhaust fumes in Denmark between 1995 and 1999, where the number of suicides committed by means of this method dropped by almost half. [5].

Our experimental reconstruction showed a momentary CO output in the vehicle exhaust of up to $790 \mathrm{ppm}$ $\left(974 \mathrm{mg} / \mathrm{m}^{3}\right)$. Such levels may be fatal under specific conditions. In accordance with the safety data sheet for CO, loss of consciousness and collapse occur at approximately $726-806 \mathrm{ppm}\left(900-1,000 \mathrm{mg} / \mathrm{m}^{3}\right)$.

\section{Conclusions}

It is very difficult to estimate the duration of $\mathrm{CO}$ exposure required for death to occur at the levels of CO measured because in a 10-min measurement, readouts of $\mathrm{CO}$ concentrations were variable in range, depending on the direction and force of wind gusts. However, there is no doubt that momentary readouts showed high $\mathrm{CO}$ concentrations that can cause loss of consciousness. A very high blood carboxyhemoglobin level (80\%) proved that the duration of $\mathrm{CO}$ exposure of the victim had was much longer than that of the experiment.

\section{References}

1 Wardaszka Z, Ptaszyńska-Sarosiek I, Niemcunowicz-Janica A. [Carbon monoxide poisoning in the autopsy material of the Department of Forensic Medicine, Medical University Of Białystok in years 1998-2008]. Arch Med Sadowej Kryminol. 2009 Jul-Sep;59(3): $177-82$.

2 Vevelstad M, Morild I. Lethal methemoglobinemia and automobile exhaust inhalation. Forensic Sci Int. 2009 May; 187(1-3):e1-5.

3 Osawa M, Horiuchi H, Yoshida K, Tada T, Harada A. A death in a stationary vehicle whilst idling: unusual carbon monoxide poisoning by exhaust gases. Leg Med (Tokyo). 2003 Mar;5 Suppl 1:S132-4.
4 Henn SA, Bell JL, Sussell AL, Konda S. Occupational carbon monoxide fatalities in the US from unintentional non-fire related exposures, 1992-2008. Am J Ind Med. 2013 Nov; 56(11):1280-9.

5 Thomsen AH, Gregersen M. Suicide by carbon monoxide from car exhaust-gas in Denmark 1995-1999. Forensic Sci Int. 2006 Aug; 161(1):41-6.

6 DiMaio VJ, Dana SE. Deaths caused by carbon monoxide poisoning in an open environment (outdoors). J Forensic Sci. 1987 Nov; 32(6):1794-5.
7 Mott JA, Wolfe MI, Alverson CJ, Macdonald SC, Bailey CR, Ball LB, et al. National vehicle emissions policies and practices and declining US carbon monoxide-related mortality. JAMA. 2002 Aug;288(8):988-95.

8 Dor F, Le Moullec Y, Festy B. Exposure of city residents to carbon monoxide and monocyclic aromatic hydrocarbons during commuting trips in the Paris metropolitan area. J Air Waste Manag Assoc. 1995;45(2):103-10.

9 Amos T, Appleby L, Kiernan K. Changes in rates of suicide by car exhaust asphyxiation in England and Wales. Psychol Med. 2001 Jul; 31(5):935-9. 